\title{
Feasibility Study on Dye Decolorization Using Microbial Cultures Supplemented with Decolorized Metabolites of Hylocereus polyrhizus
}

\author{
Jen-Hung Yuan, Chung-Chuan Hsueh, Bor-Yann Chen* \\ Department of Chemical and Materials Engineering, Nation Ilan University, Ilan, Taiwan \\ Email address: \\ filly2468@gmail.com (Jen-Hung Yuan), cchsueh88@gmail.com (Chung-Chuan Hsueh), boryannchen@yahoo.com.tw (Bor-Yann Chen) \\ ${ }^{*}$ Corresponding author
}

\section{To cite this article:}

Jen-Hung Yuan, Chung-Chuan Hsueh, Bor-Yann Chen. Feasibility Study on Dye Decolorization Using Microbial Cultures Supplemented with Decolorized Metabolites of Hylocereus polyrhizus. Science Discovery. Vol. 4, No. 2, 2016, pp. 116-121. doi: 10.11648/j.sd.20160402.20

Received: February 28, 2016; Accepted: May 13, 2016; Published: May 18, 2016

\begin{abstract}
This feasibility study used indigenous microbes to implement assessment upon capabilites of dye decolorization with supplementation of decolorized metabolites (DM) of Hylocereus polyrhizus. As indicated, ca. 5\% DM of Hylocereus polyrhizus could clearly exhibit reversible redox peak potentials via cyclic voltammetric analysis, revealing its significant capability as electron-shuttling mediators. Compared to DM-supplemented decolorization, the ranking of dye-decolorizing capabilities of bacteria was Shewanella putrefaciens WLP72> Enterobacter cancerogenus BYm30>Aeromonas hydrophila NIU01 A. hydrophila YT11 > Klebsiella pneumoniae ZMd31. The ranking of biodegradability of azo dyes was RB160 > RBk5 $>$

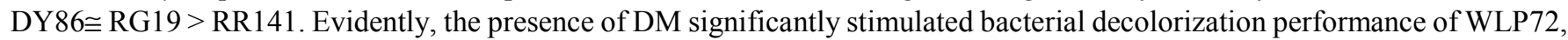
BYm30, ZMd31. However, possibly due to inhibitory characteristics of DM to A. hydrophila, its dye decolorization was delayed. That is, using DM to enhance dye decolorization, biodecolorizers should be acclimated in such envionments for effective expression. The findings also pointed out that supplementation of DM to YT11, WLP72 at ca. 10 15\% for decolorization of RR141 could effectively increase dye-decolorizing efficiency ca. $2.33 \sim 2.88$ fold. Such DM augmentation inevitably could autocatalytically stimulate electron transfer capabilities for optimal wastewater decolorization with sustainable development.
\end{abstract}

Keywords: Electron-shuttles, Dye decolorization, Hylocereus polyrhizus

\section{火龍果脫色代謝物應用於染料脫色之可行性評估}

\author{
袁任宏, 薛仲娟, 陳博彥*
}

化學工程與材料工程學系, 國立宜蘭大學, 宜蘭, 台灣

\section{邮箱}

i11y2468@gmai1.com(袁任宏), cchsueh88@gmai1.com(薛仲娟), boryannchen@yahoo. com.tw(陳博彥)

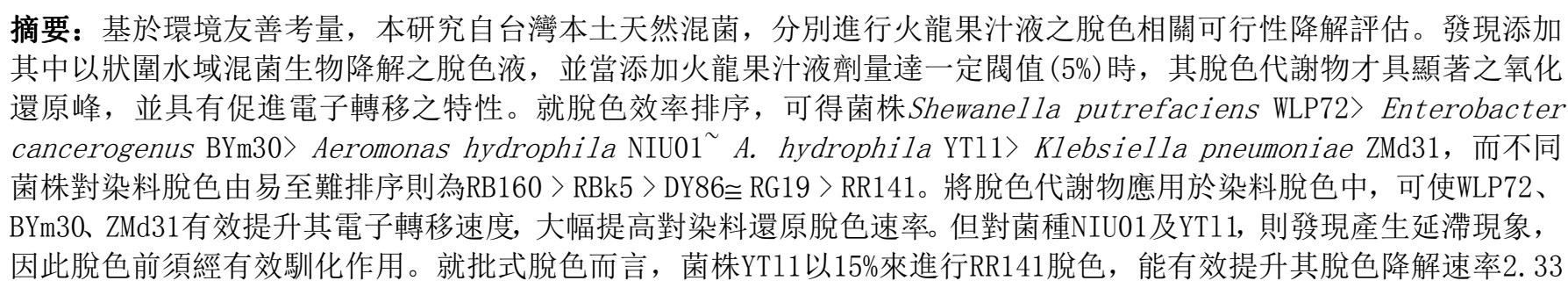


倍, 就菌株WLP72而言添加脫色代謝物之脫色降解速率皆遠大於未添加者, 並當添加 $10 \%$ 時, 即有效提升其脱色降解速 率2.88倍。此種天然染料脱色代謝物之添加策略可用於染料廢水處理自催化促進處理之工程優化上。

關鍵字: 電子中介體, 染料脫色, 火龍果

\section{1. 引言}

染料工業廢水中所殘留之染料、色素等汗染物，由於 顯而易見之特性, 不可避免地其處理儼然已是環保單位必 查之重點項目之一。由於利用化學、物理 (例如:吸附、凝 聚、氧化、電化學) [1-3]等非生物方法進行分解處理時, 仍存諸多缺點: 如高能量成本、高汗泥產量、有二次污染 之虞等。因此基於綠色永續理念, 環境生態友善之生物處 理技術, 已成汗染處理之熱點。尤其由原汗染場址篩選之 本土微生物菌相 (株) 富集培養來進行降解汙染染料或色 素, 取之於自然, 回歸於自然, 更是一種普遍公認綠色友 善之處理方法 $[4]$ 。

工業染料由於生物分解性低, 不易被氧化。因此脫色 處理多以厭氧條件進行。先前研究更發現 [1], 脫色產生之 芳香胺中間物具有電子中介作用, 可有效促進染料脱色及 電子移轉之能力, 因此更深入探索在 $-\mathrm{OH},-\mathrm{NH}_{2},-\mathrm{N}\left(\mathrm{CH}_{3}\right) \mathrm{H}$, $-\mathrm{N}\left(\mathrm{CH}_{3}\right)_{2}$ 等官能基存在下之電子傳遞能力差異進行比較。其 中此類中間物於電化學特性上, 具有可逆之氧化還原峰, 亦以此點為指紋辨識指標, 再深入研究脫色代謝物亦可能 具有此特性。本研究基於環境友善考量, 更進一步深入針 對果菜公司可能產生果菜汁廢水進行可行性處理初探研究, 期盼自廢液中取出具有此種特性之成份富集, 再深入應用 於染料廢水處理生物刺激上之運用。本研究取定有色蔬果 個案火龍果為例, 因含有天然色素-甜菜苷 (Betanin), 具 有天然、抗氧化、水溶性、色彩鮮艷等特性, 因此是極佳 研究對象, 若進行處理染料廢水時, 可予以環境友善地添 加來促進脫色。基於此, 首先自東北台灣本土選定狀圍水 域、日月潭、宜蘭大學大學池等三處水體樣本混合菌相, 分別對紅肉火龍果所萃取出之汁液進行初步可行性降解評 估。研究中發現以狀圍水域混菌確實對火龍果汁液產生有 效生物降解, 更發現脫色中間物, 具有促進電子轉移之可 逆氧化還原峰之特性。更可有效運用於生物電化學方式處 理上(例如: 微生物燃料電池 (MFC)), 並同時應用於染料脫 色中, 來有效提升電子轉移速度, 大幅提高其對污染染料 降解速度 $[5]$ 。本研究發現要有效對火龍果進行脫色, 可能 不少微生物皆可進行, 但是論及產生具有可逆氧化還原峰 之特性產物, 則僅特定微生物方可行之, 因此本研究更將 提出較可行之生物處理操作模式來做實際應用。以利於廣 泛應用於工業廢水處理之生物刺激相關應用。

\section{2. 材料與方法}

\section{1. 水樣前處理}

將取得之壯圍水域、日月潭、宜蘭大學大學池三種不 同的水體水樣分別取 $100 \mathrm{ml}$, 添加 $0.1 \mathrm{~g}$ 紐徽素, 取用 N0.2 試紙進行粗顆粒之初節。

\section{2. 火龍果汁液萃取}

取紅肉火龍果 (Hylocereus polyrhizus) 約 $200 \mathrm{~g}$ ，去除 果皮後, 將果肉約 $170 \mathrm{~g}$ 研磨成果泥後, 再以高速離心機 (11000rpm、 $\left.25^{\circ} \mathrm{C} 、 15 \mathrm{~min}\right)$ 進行離心, 後取其上層液 $120 \mathrm{ml}$, 再以 $0.24 \mu \mathrm{m}$ 孔徑濾紙濾除顆粒固體, 以利於後續作初步分析。

\section{3. 微生物前培養}

將經前處理取得之壯圍水域、日月潭、宜蘭大學大學 池三種不同的水體水樣, 分別取 $0.5 \mathrm{~m} 1$ 加入預先經滅菌 LB 培養基培養液 $50 \mathrm{ml}$, 進行搖瓶 $\left(30^{\circ} \mathrm{C} 、 125 \mathrm{rpm}\right)$ 前培養十二 小時後活化後, 再以凍管形式保存於 $50 \%(\mathrm{v} / \mathrm{v})$ 甘油, 並庫 存於 $-85^{\circ} \mathrm{C}$ 超低溫冷凍櫃中, 以利後續研究應用。

\section{4. 搖瓶脫色測試}

將活化後之菌液取 $(1 \%$, 即 $0.5 \mathrm{ml})$, 置入含 $50 \mathrm{ml} \mathrm{LB}$ 培養基之搖瓶, 並加入相對於培養基為 $1 \%$ 、5 \%、10\%含量 之火龍果滤汁原液 (分別於 $0.5 \mathrm{~m} 1 、 2.5 \mathrm{~m} 1 、 5 \mathrm{~m} 1$ ) 後, 以 $30^{\circ} \mathrm{C}$ 、 $125 \mathrm{rpm}$ 條件下搖瓶培養6小時後, 開始靜置脫色至其脫色, 並追踪量測率達 $95 \%$ 。

\section{5. 循環伏安法}

分別針對本脫色菌液、原果汁液, 以及脫色完之濾菌 上清液, 進行高速離心 $\left(11000 \mathrm{rpm} 、 25^{\circ} \mathrm{C} 、 10 \mathrm{~min}\right)$ 取其上 澄液, 利用循環伏安法掃描電位之特色搜尋氧化還原電位, 確認氧化還原電位後, 將液體備份保存, 由峰電位與峰電 流的變化情形來推測電化學特性, 作為是否有促進電子轉 移的電子梭可能應用性 (掃描範圍 $0.4^{\sim}-0.6 \mathrm{~V}$; 掃描速率 $10 \mathrm{mV} \mathrm{s}^{-1}$; 循環次數 3 cycles)

\section{3. 結果與討論}

\section{1. 定性分析比較}

表 1 三種水樣 (a) 分別對火龍果汁液進行脫色 (b) 經 $1 \%$ 火龍果汁液馴養 後分別對 $1 \%$ 火龍果汁液進行脫色 (c) 經 $1 \%$ 火龍果汁液馴養後分別對 $5 \%$ 火 龍果汁液進行脫色 (d) 經 $5 \%$ 火龍果汁液馴養後分別對 $10 \%$ 火龍果汁液進 行脫色之分析比較。

\begin{tabular}{|c|c|c|c|}
\hline (a) & 大學池 & 日月潭 & 壯圍海水 \\
\hline$X_{\mathrm{u}}$ & $+/-$ & $+/-$ & $+/-$ \\
\hline$X_{u}+$ 火龍果汁液 (未脫色前) & - & - & - \\
\hline$X_{u}+$ 火龍果汁液 (脫色後) & $+/-$ & $+/-$ & ++ \\
\hline (b) $1 \% \rightarrow 1 \%$ & 大學池 & 日月潭 & 壯圍海水 \\
\hline $\mathrm{X}_{\mathrm{a}}+$ 火龍果汁液 (未脫色前) & - & - & - \\
\hline $\begin{array}{l}X_{a}+\text { 火龍果汁液 (脫色後) } \\
1 \% \rightarrow 1 \%(\mathrm{PBS})\end{array}$ & $+/-$ & $+/-$ & $+/-$ \\
\hline $\mathrm{X}_{\mathrm{a}}+$ 火龍果汁液 (未脫色前) & - & - & - \\
\hline $\mathrm{X}_{\mathrm{a}}+$ 火龍果汁液 (脫色後) & $+/-$ & $+/-$ & $+/-$ \\
\hline
\end{tabular}




\begin{tabular}{|c|c|c|c|}
\hline (c) $1 \% \rightarrow 5 \%$ & 大學池 & 日月潭 & 壯圍海水 \\
\hline $\mathrm{X}_{\mathrm{a}}+$ 火龍果汁液 (未脫色前) & - & - & - \\
\hline $\begin{array}{l}X_{\mathrm{a}}+\text { 火龍果汁液 (脫色後) } \\
1 \% \rightarrow 5 \%(\mathrm{PBS})\end{array}$ & $+/-$ & $+/-$ & $+/-$ \\
\hline $\mathrm{X}_{\mathrm{a}}+$ 火龍果汁液 (未脫色前) & - & - & - \\
\hline$X_{a}+$ 火龍果汁液 (脫色後) & $+/-$ & $+/-$ & ++ \\
\hline (d) $5 \% \rightarrow 10 \%$ & 大學池 & 日月潭 & 壯圍海水 \\
\hline $\mathrm{X}_{\mathrm{a}}+$ 火龍果汁液 (未脫色前) & - & - & NT \\
\hline $\begin{array}{l}X_{\mathrm{a}}+\text { 火龍果汁液 (脫色後) } \\
5 \% \rightarrow 10 \%(\mathrm{PBS})\end{array}$ & $+/-$ & $+/-$ & NT \\
\hline$X_{a}+$ 火龍果汁液 (未脫色前) & - & - & NT \\
\hline$X_{\mathrm{a}}+$ 火龍果汁液 (脫色後) & $+/-$ & $+/-$ & NT \\
\hline
\end{tabular}

++ 表具脫色能力且有氧化還原峰

- 表無氧化還原峰

+/-表具脫色能力但無氧化還原峰

$X_{\mathrm{u}}$ 表未經火龍果汁液馴養

$X_{a}$ 表已經火龍果汁液馴養

NT表未試驗

*火龍果汁液、LB培養基無氧化還原峰
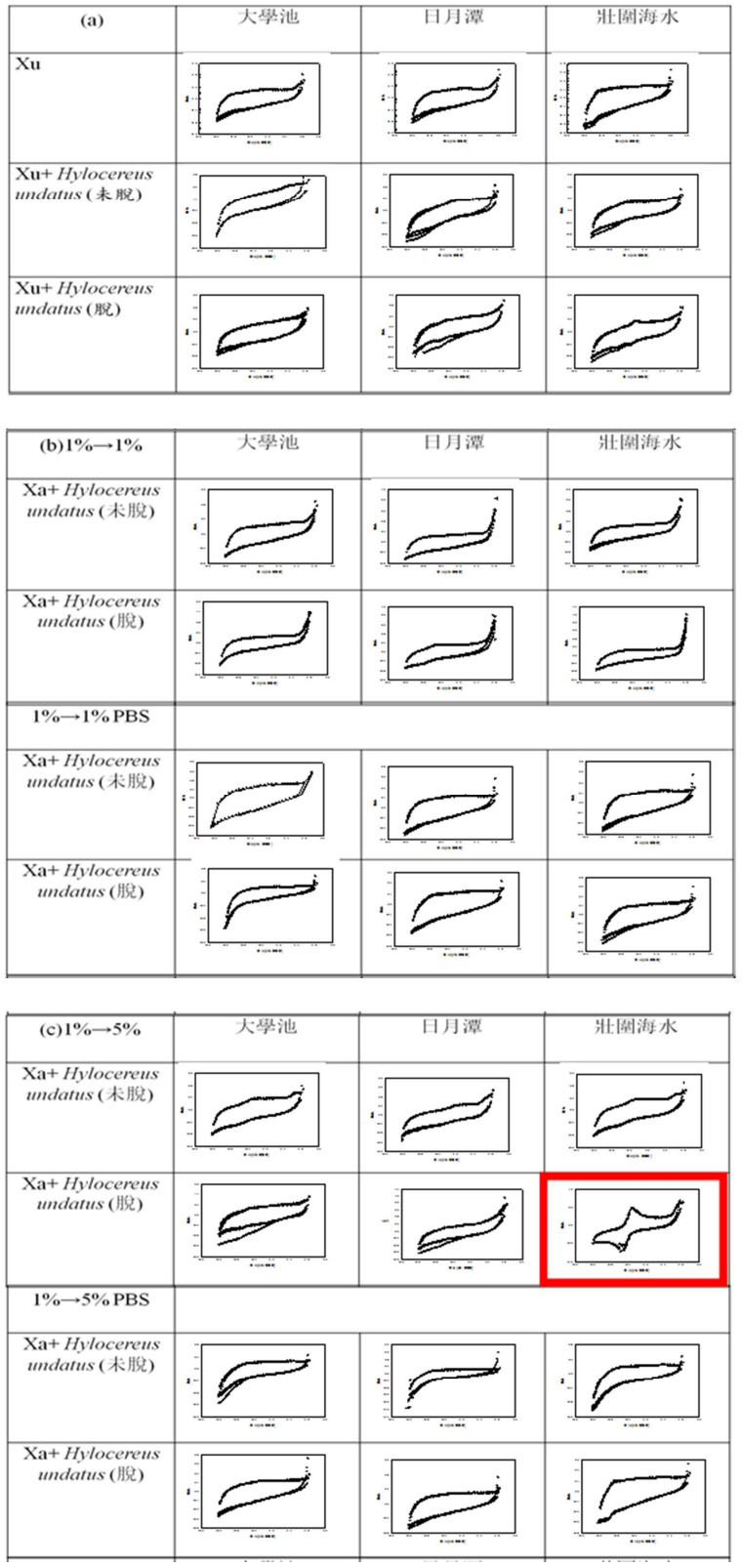

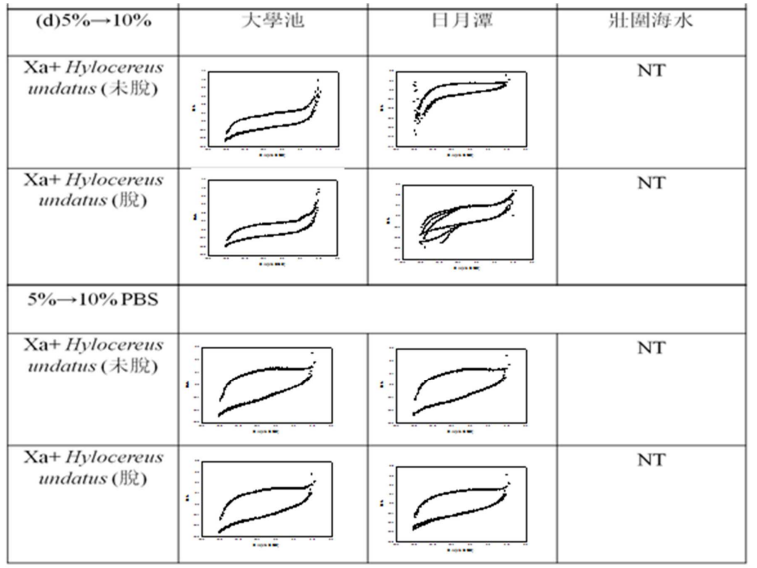

圖1 三種水樣 (a) 分別對火龍果汁液進行脫色 (b) 經 $1 \%$ 火龍果汁液馴羪 後分別對 $1 \%$ 火龍果汁液進行脫色 (c) 經 $1 \%$ 火龍果汁液馴養後分別對 $5 \%$ 火 龍果汁液進行脫色 (d) 經 $5 \%$ 火龍果汁液馴養後分別對 $10 \%$ 火龍果汁液進 行脫色之分析比較。

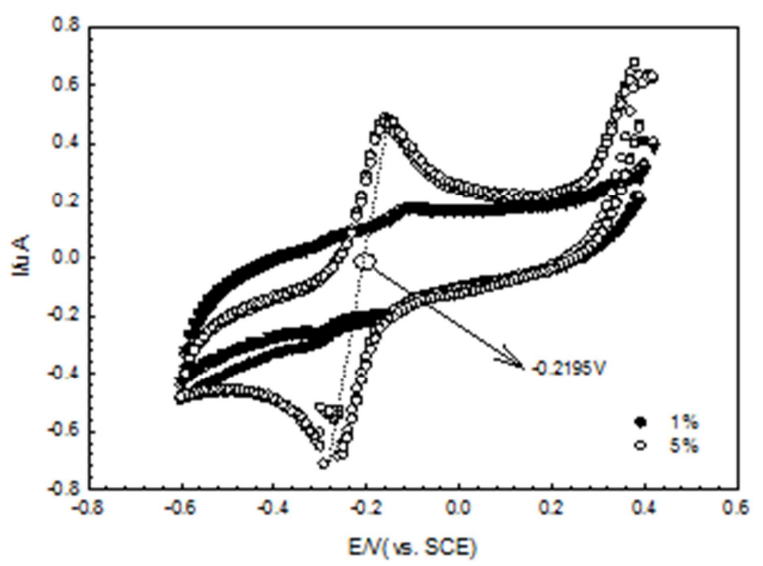

（箭頭所指為 $\mathrm{E}$ '0約-0.2195V)

圖2 壯圍混菌經添加 $1 \%$ 、5 \% 火龍果汁液脫色後之循環伏安圖。

$$
\begin{aligned}
& \mathrm{E}{ }_{0}=\left(\mathrm{E}_{\mathrm{pa}}+\mathrm{E}_{\mathrm{pc}}\right) / 2, \quad \text { (vs. SCE) } \\
& \mathrm{n}^{\mathrm{c}}=\left(\left|\mathrm{E}_{\mathrm{pc}}-\mathrm{E}_{\mathrm{pa}}\right|\right) / 57(\mathrm{mV})
\end{aligned}
$$

E 。應介於主要電子供體與與最終電子受體之間，才 具備電子轉移之功效, 而 $\mathrm{NADH}$ 的氧化還原電位是 $-0.32 \mathrm{~V}$ (vs. NHE), 因此氧化還原電位需高於- $0.32 \mathrm{~V}$ 方具備 從生物體上轉移電子之能力 [6] [7]。而公式 (2) 為電子轉

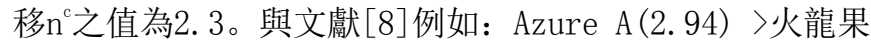
脫色代謝物 (2.3) >Azure C (2.05) >Thionine (1.16)。

表1 (a) 可判斷就單純三處水源混菌以LB培養基活化 後, 所生代謝物並不具電子移轉氧化還原峰。亦即原生菌 本身並不具有電子梭物質之可能, 表 1 (b) 則可看出以三處 水源混菌對添加相對其LB培養基 $1 \%$ 火龍果汁液行脫色, 其 脫色代謝物, 僅狀圍混菌對火龍果汁液行脫色後之脫色代 謝物可能具些微氧化還原峰。此結果有可能是火龍果汁液 添加濃度不足脫色, 因此提高劑量至少需達到 $5 \%$ 汁液再次 進行測試。表 1 (c) 及圖2中可知，當火龍果汁液添加至 $5 \%$ 後, 狀圍混菌對火龍果汁液行脫色後之脫色代謝物其氧化 還原峰更為明顯, 因此可知添加劑量實是一重大因素。但 是大學池、日月潭兩者混菌添加在火龍果汁液 $5 \%$ 脫色，其 
脫色代謝物卻不具備氧化還原峰。表4更指出添加火龍果 汁液達 $10 \%$, 大學池、日月潭兩者其脫色代謝物仍不具氧 化還原峰。上述之結果可知, 以狀圍混菌對火龍果汁液 $5 \%$ 進行脫色之代謝物確實具有顯著氧化還原峰。而且若脫色
汁液欲顯出顯著電子轉移特性, 仍須有相當劑量反應才能 起作用, 亦即至少含量要達到一臨界閥值以上, 所分解代 謝物才能有顯著氧化還原峰特性, 以利於後續染料廢水之 相關應用。

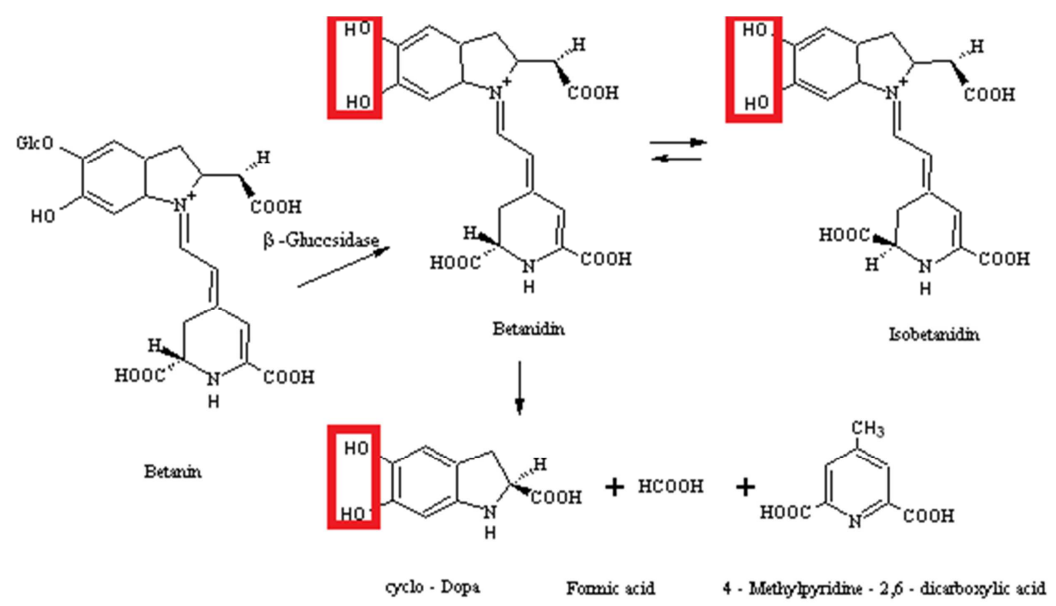

圖3 Betanin降解可能途徑圖 [9]。

表2 不同菌種添加5\%火龍果DM後之脫色反應。

\begin{tabular}{|c|c|c|c|c|}
\hline & \multicolumn{2}{|l|}{ WLP72 } & \multicolumn{2}{|l|}{ BYm30 } \\
\hline & Blank & DM & Blank & DM \\
\hline RB160 & $0.25 \mathrm{~h}^{+}, \quad 0.3 \mathrm{~h}^{++}$ & $0.25 \mathrm{~h}^{++}$ & $0.25 \mathrm{~h}^{+}, \quad 0.3 \mathrm{~h}^{++}$ & $0.25 \mathrm{~h}^{++}$ \\
\hline RBk5 & $0.25 \mathrm{~h}^{+}, \quad 0.3 \mathrm{~h}^{++}$ & $0.25 \mathrm{~h}^{++}$ & $0.75 \mathrm{~h}^{+}, 1.25 \mathrm{~h}^{++}$ & $0.75 \mathrm{~h}^{++}$ \\
\hline RG19 & $0.25 \mathrm{~h}^{+}, \quad 0.3 \mathrm{~h}^{++}$ & $0.25 \mathrm{~h}^{++}$ & $0.75 h^{+}, 1.25 h^{++}$ & $0.75 h^{+}$ \\
\hline RR141 & $0.25 \mathrm{~h}^{+}, \quad 0.3 \mathrm{~h}^{++}$ & $0.25 \mathrm{~h}^{++}$ & $0.75 \mathrm{~h}^{+}, 1.25 \mathrm{~h}^{++}$ & $0.75 \mathrm{~h}^{++}$ \\
\hline \multirow[t]{2}{*}{ DY86 } & $\begin{array}{l}0.25 \mathrm{~h}^{+}, \quad 0.3 \mathrm{~h}^{++} \\
\text {ZMd31 }\end{array}$ & $0.25 \mathrm{~h}^{++}$ & $\begin{array}{l}0.75 h^{+}, 1.25 h^{++} \\
\text {NIU01 }\end{array}$ & $0.75 \mathrm{~h}^{++}$ \\
\hline & Blank & DM & Blank & DM \\
\hline RB160 & $12 \mathrm{~h}^{+}, 24 \mathrm{~h}^{++}$ & $12 \mathrm{~h}^{++}$ & $1 h^{++}$ & $1 \mathrm{~h}^{+}, 2 \mathrm{~h}^{++}$ \\
\hline RBk5 & $24 \mathrm{~h}^{-}, 36 \mathrm{~h}^{ \pm}, 60 \mathrm{~h}^{ \pm}$ & $24 h^{+}, 36 h^{++}$ & $1 h^{++}$ & $1 \mathrm{~h}^{+}, 2 \mathrm{~h}^{++}$ \\
\hline RG19 & $36 h^{ \pm}, 48 h^{ \pm}, 60 h^{ \pm}$ & $36 \mathrm{~h}^{+-}, 48 \mathrm{~h}^{++}$ & $1 h^{++}$ & $1 \mathrm{~h}^{+}, 2 \mathrm{~h}^{++}$ \\
\hline RR141 & $48 \mathrm{~h}^{ \pm}, 60 \mathrm{~h}^{ \pm}$ & $48 \mathrm{~h}^{+}, 60 \mathrm{~h}^{++}$ & $1 h^{++}$ & $1 \mathrm{~h}^{+}, 2 \mathrm{~h}^{++}$ \\
\hline \multirow[t]{2}{*}{ DY86 } & $\begin{array}{l}36 \mathrm{~h}^{-}, 48 \mathrm{~h}^{+-}, 60 \mathrm{~h}^{++} \\
\text {YT11 }\end{array}$ & $36 \mathrm{~h}^{+-}, 48 \mathrm{~h}^{++}$ & $1 h^{++}$ & $1 \mathrm{~h}^{+}, 2 \mathrm{~h}^{++}$ \\
\hline & Blank & DM & & \\
\hline RB160 & $1.5 \mathrm{~h}^{++}$ & $1.5 \mathrm{~h}^{+}, 1.75 \mathrm{~h}^{++}$ & & \\
\hline RBk5 & $3.5 \mathrm{~h}^{+}, \quad 4.5 \mathrm{~h}^{++}$ & 3. $5 \mathrm{~h}^{++}$ & & \\
\hline RG19 & $3.5 \mathrm{~h}^{+-}, 5^{+}, 7 \mathrm{~h}^{++}$ & 3. $5 \mathrm{~h}^{+}, 5 \mathrm{~h}^{+}$ & & \\
\hline RR141 & $4 \mathrm{~h}^{+-}, 5 \mathrm{~h}^{+}, 6 \mathrm{~h}^{++}$ & $4 h^{+}, 5 h^{++}$ & & \\
\hline DY86 & $4 \mathrm{~h}^{+-}, 5 \mathrm{~h}^{+}, 6 \mathrm{~h}^{++}$ & $4 h^{+}, 5 h^{++}$ & & \\
\hline
\end{tabular}

Color removal > 95\%

Color removal ca. $75 \%$

Color removal ca. $50 \%$

${ }^{ \pm}$Color removal ca. $25 \%$

Insignificant color removal

在以化學結構眼光來看, 文獻 [5]指出, 若於苯環羥基 的鄰位或對位下, 具有官能基 (如殌基或胺基) 當接受端, 能接受在苯環內的自由電子或正電荷, 且能以共振形式使 電子得以有效轉移並傳彪, 即具備成為電子梭之基本條件。 由文獻 [9] 火龍果主要成分色素Betanin的可能代謝降解途 徑中, 推測可能產生Betanidin, Isobetanidin、cyclo-DOPA 三種化合物, 本研究推論可能具有電子梭之條件, 因 $-\mathrm{OH}$ 官能基鄰位存在可能具氧化還原峰之能力, 後續研究將再 深入GC-MS進行解析比對, 判斷是何種物質可能是狀圍混菌
對火龍果汁液進行脫色反應後之脫色代謝物可能電子轉移 之產物。(betanin不具氧化還原峰, 數據未列)

根據先前研究 [10], 添加具電子梭效果之脫色中間物 後, 菌株對染料之脫色效率可有明顯提升, 表 5 更得知除 NIU01、YT11外, 其於菌株在添加過脫色中間物後, 其脫 色效率皆明顯提升。而由表 2 得知菌株對染料脫色難易為 （RB160>RBk5>DY86 $\fallingdotseq R G 19>R R 141 ）$ ，與文獻 [11] 中表1，染 料RB160最易脫色，而RR141則較難脫色現象相符。在文獻 [12] 中菌株 ZMd44 之染料脫色 SDR 為 RBu160 (14.62) > RG19 (3.47)>RBk5 (3.40)>RR141 (2.22) ; 菌株 NIU01 之染料脫色 SDR 為 RBk5 (80.9) > RR141 (66.5)> RG19 (23.2), 同樣可看出 RB160最易脫色, 再者是RBk5。而在菌株對染料脫色能力 大 小依序 (Shewanella putrefaciens WLP72> Enterobacter cancerogenus BYm30> Aeromonas hydrophila NIU01>Aeromonas hydrophila YT11> Klebsiella pneumoniae ZMd31), 文獻 [4] 中菌株 NIU01>ZMd31對染料RB160明顯脫色能力相符。

\section{2. 狀圍混菌之火龍果DM應用於脫色處理之成效}

為深入探討添加脫色中間物之促進效果, 取定與 NIU01同為Aeromonas hydrophila[11]之YT11來進行脫色 研究, 發現未經馴養之菌株YT11, 會產生延滯現象 (數據 未列)。故圖4為菌株YT11經壯圍混菌的火龍果脫色中間物 馴養 12 小時後, 分別添加不同濃度 (5\%、10\%、15\%) 的壯圍 混菌之火龍果脫色中間物, 對染料RR141進行脫色試驗, 由結果得知其 $\operatorname{SDR}$ (單位: $\left.\mathrm{mg} \mathrm{L}^{-1} \mathrm{~h}^{-1} O D U^{-1}\right)$ 為 (15\% (8.31) $>$ blank (3. 57) $\fallingdotseq 10 \%(3.19)>5 \%(2.18))$, 代表要促進脫色, 至少劑量需提高至15\%, 能使脫色速率提升2.33倍, 有效 劑量下發現當添加較高濃度的脫色中間物 (具電子梭能力) 顯示出脫色速率越快之劑量影響關係。如此結果代表於染 料廢水處理添加天然有色蔬果生體或微生物, 確實是可行 之操作策略。 


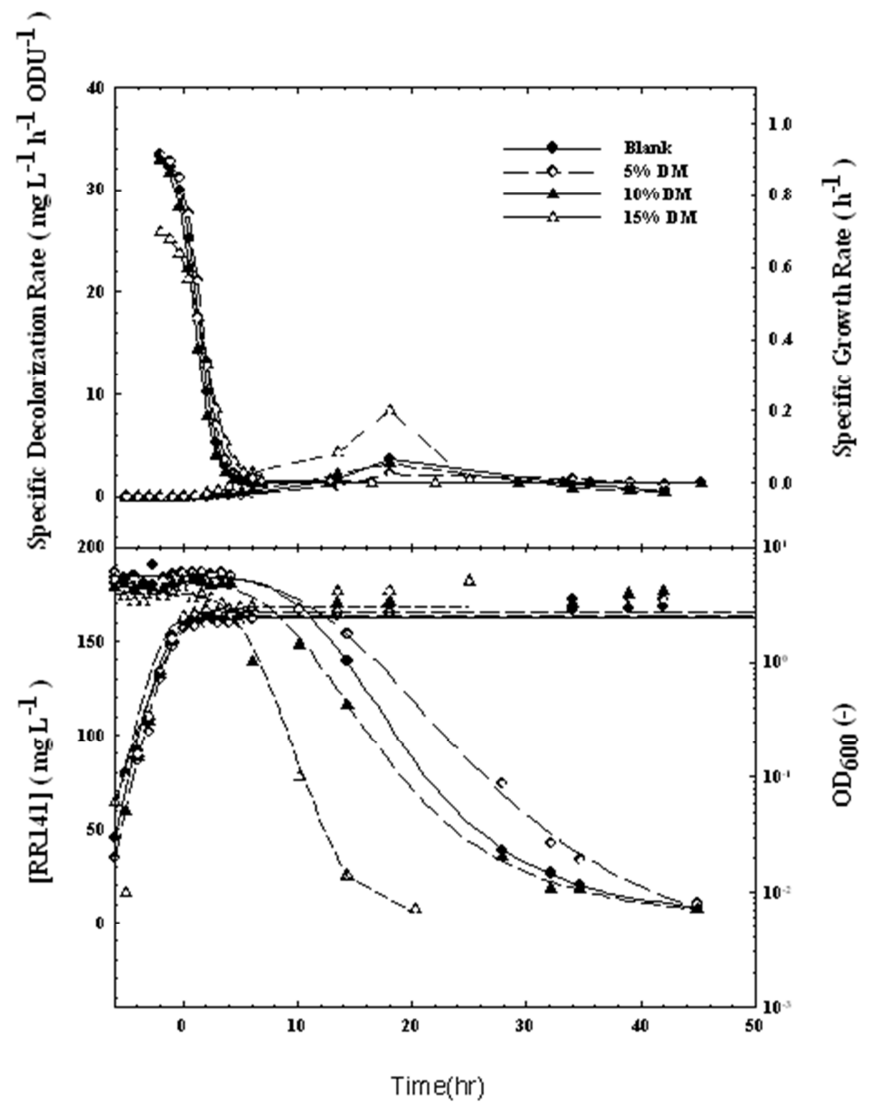

圖4 經壯圍混菌脫色之火龍果脫色中間物添加於經脫色中間物馴養之YT11進行RR141脫色曲線圖。

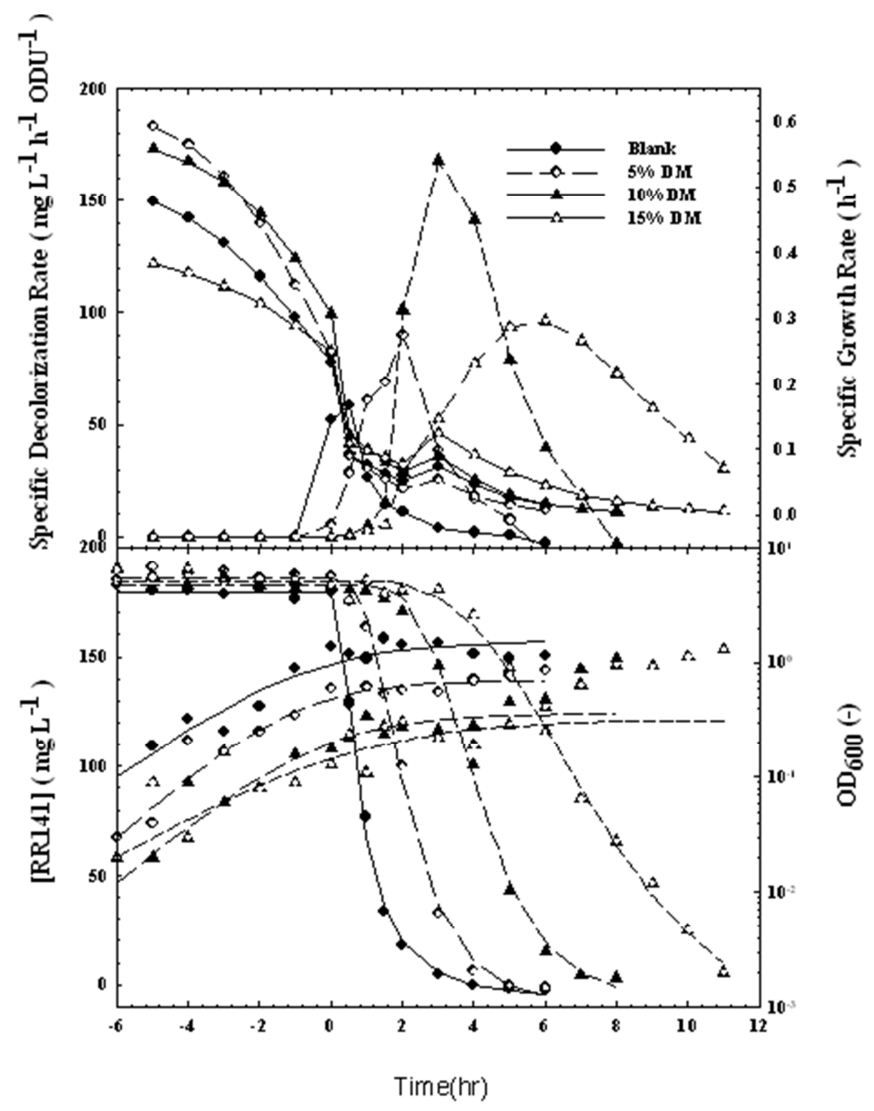

圖5 經壯圍混菌之火龍果中間物添加於RR141之WLP72搖瓶培養液之脫色成效圖。 
由於脫色效率最佳為菌株WLP72, 因此取定來進行脫 色比較, 自圖5可發現, 隨著添加之脫色物濃度提升, 對 菌種生長抑制效果越強 (亦即菌體量下降), 但就SDR而言 為 (單位： $\mathrm{mg} \mathrm{L} \mathrm{L}^{-1} \mathrm{~h}^{-1} \mathrm{ODU}^{-1}$ ) 為 $(10 \%$ (167.84) >15\%(96.45) $>5 \%$ (90.05) >blank (58.22)), 顯示添加脫色代謝物能有 效提升降解速率。

\section{4. 結論及未來展望}

以本土大學池、日月潭兩處水源混菌對火龍果汁液進 行脫色, 其脫色代謝物不具氧化還原峰, 只有以狀圍水源 混菌對火龍果汁液進行脫色, 且在添加劑量達一定閥值 (5\%) 時, 其脫色中間物才具顯著氧化還原峰。而其脫色代 謝物, 因具備電子梭效果, 可有效提升電子轉移速度, 並 提高大多數微生物對污染染料降解速度。結果發現菌株 WLP72、BYm30、ZMd31在添加5\%濃度之脫色中間物時, 對 染料降解具有顯著之提升。而菌株NIU01、YT11則產生延 滯現象, 與菌株NIU01同為Aeromonas hydrophila之菌株 YT11, 搖瓶脫色結果顯示, 添加火龍果脫色代謝物濃度達 15\%可更明顯提升其脫色速率, 但菌體YT11需先經過脫色 中間物之適應, 以避免延滯現象。而就菌體WLP72搖瓶脫 色結果顯示, 火龍果脫色代謝物, 雖會抑制菌體生長, 但 添加火龍果脫色代謝物確實能有效提升脫色效率。未來將 進行當菌體WLP72達到一定濃度時, 再進行添加染料及火 龍果脫色代謝物之搖瓶脫色試驗, 並以GC-MS檢測, 確定 脫色代謝物中為何種物質, 以及是否具氧化還原峰, 以利 用於染料廢水處理。

\section{致謝}

感謝科技部計畫：MOST 102-2221-E-197-016-MY3與 MOST 104-2622-E-197-006-CC3之經費補助。

\section{參考文獻}

[1] Lin, S. H., Peng, C. F., “Continuous treatment oftextile wastewater by combined coagulation, electrochemical oxidation and activated sludge, ” Volume 30, 1996, p 587-592.

[2] Lin, S. H., Peng, C. F., “Treatment of textilewastewater by electrochemical method," Volume 28, 1994, p 277-282.

[3] Nuttapun, S., Kanchana, J., Somsak, D., Delia, M. L., Pierre, S., "Microbial decolorization of reactive azo dyes in a sequential naerobic - aerobic ystem, ” Volume 99, Issue 2, 2004, p 169-176.

[4] Chen, B. Y., Chen, W. M., Wu, F. L., Chen, R. K., Yen, C. Y., "Revealing azo-dye decolorization of indigenous Aeromonas hydrophila from fountain spring in Northeast Taiwan, " Volume 39, Issue 5, 2008, p $495-501$.

[5] Chen, B. Y., Hsueh, C. C., Liu, S. Q., Ng, I. S., Wang, Y. M., "Deciphering mediating characteristics of decolorized intermediates for reductive decolorization and bioelectricity generation, ” Volume 145, 2013, p $321-325$.

[6] Chen, B. Y., Xu, B., Yueh, P. L., Han, K., Qin, L., Hsueh, C. C., Xia, Y., "Exploring Microbial Fuel Cell-assisted Bioremediation of Textile Dyes: Energy Conversion," Volume 1, 2015, p 11-18.

[7] Sun, J., Li, W., Li, Y., Hu, Y., Zhang, Y., "Redox mediator enhanced simultaneous decolorization of azo dye and bioelectricity generation in air-cathode microbial fuel cell," Volume 142, 2013, p 407-414.

[8] Chen, B. Y., Xu, B., Yueh, P. L., Han, K., Qin, L., Hsueh, C. C., “Deciphering electron-shuttling characteristics of thionine-based textile dyes in microbial fuel cells, "Volume 51, 2015, p 63-70.

[9] Naoko, K., Jürgen, S., Victor, W., Willibald, S., "Formation and occurrence of dopamine-derived betacyanins, ” Volume 56, Issue 5, 2001, p $429-436$.

[10] Xu, B., Chen, B. Y., Hsueh, C. C., Qin, L. J., Chang, C. T., "Deciphering characteristics of bicyclic aromatics - mediators for reductive decolorization and bioelectricity generation, " Volume 163, 2014, p $280-286$.

[11] Zhang, M. M. , Chen, W. M., Chen, B. Y., Chang, C. T., Hsueh, C. C., Ding, Y., Lin, K. L., Xu, H., "Comparative study on characteristics of azo dye decolorization by indigenous decolorizers, " Volume 101, Issue 8, 2010, p 2651-2656.

[12] Chen, B. Y, Zhang, M. M., Changc, C. T., Ding, Y., Lin, K. L., Chiou, C. S., Hsueha, C. C., Xu, H., "Assessment upon azo dye decolorization and bioelectricity generation by Proteus hauseri," Volume 101, Issue 12, 2010, p $4737-4741$. 